\title{
Conformation of the Antigenic Peptide Tyrosinase (192-200) in Water and DMSO-d6 by NMR Spectroscopy and MD Simulations
}

\section{Evans C Coutinho ${ }^{1^{*}}$, Mishra NB ${ }^{1}$, Deep Bhattacharya ${ }^{1}$, Sudha Srivastava ${ }^{2}$, Mamata Joshi ${ }^{2}$ and Mushtaque Shaikh ${ }^{1}$}

${ }^{1}$ Department of Pharmaceutical Chemistry, Bombay College of Pharmacy, Kalina, Santacruz [E], India

${ }^{2}$ National Facility for High Field NMR, Tata Institute of Fundamental Research, Homi Bhabha Road, Navy Nagar, Colaba, India

\begin{abstract}
Melanomas represent the most resistant form of cancer. If detected early, a cure is possible with the conventional therapies, while metastatic forms are almost resistant to conventional therapies. A new area i.e. immune based therapy shows promise of cytolytic activity against tumor cells. Production of antibodies against the antigenic epitopes present in the melanoma is the main basis of this immune based therapy. Production of $T$ cell response against the tumor cells has been seen by synthetic antigenic epitopes. The antigenic nonameric peptide epitope of tyrosinase (192-200) with the sequence $S^{1} E$ EIWR $^{5}$ DIDF $^{9}$ causes significant induction of the $T$ cell response in melanoma patients. In realm of the significance of this peptide, a solution state NMR structure of 192-200 amino acid section of tyrosinase has been investigated, to assimilate the relationship between the antigenicity and the conformation of the peptide. NMR studies were carried out in $\mathrm{H}_{2} \mathrm{O}: \mathrm{D}_{2} \mathrm{O}(95: 5)$ and DMSO- $\mathrm{d}_{6}$ solvents. Molecular dynamics simulations with NMR constraints were carried out using the GROMACS v .4.6.5 package. The results suggest the prevalence of a $\beta$-sheet structure both in $\mathrm{H}_{2} \mathrm{O}$ as well as in DMSO- $\mathrm{d}_{6}$.
\end{abstract}

\begin{abstract}
Abbreviations: DMSO-d : Dimethyl Sulfoxide- $\mathrm{D}_{6}$; TAA: Tumor Associated Antigen; MAA: Melanoma Associated Antigens; Ctls: Cytolytic T Cell Lymphocytes; TCR: T Cell Receptor; APC: Antigenic Presenting Cell; HLA: Human Leukocyte Antigens; TRP: TyrosinaseRelated Protein; TSP: 3-(Trimethylsilyl)Propanoic Acid, TOCSY: Total Correlation Spectroscopy, ROESY: Rotating Frame Overhauser Effect Spectroscopy; Roe: Rotating Frame Overhauser Effect; RMSD: Root Mean Square Deviation, OPLS: Optimized Potentials For Liquid Simulations, PDB: Protein Data Bank; Ppb: Parts Per Billion
\end{abstract}

Keywords: Nuclear magnetic resonance; Tyrosinase (192-200); Molecular dynamics simulations; Antigenic peptide; GROMACS

\section{Introduction}

Melanoma is a malignant tumor of the melanocytes which are pigment producing cells in the skin [1]. It is the major cause of deaths related to skin cancers. Although melanoma is completely curable by classical therapies such as surgery at an early stage, metastatic melanoma is many a times resistant to classical therapies [2]. Thus, there is an immediate need for new therapeutic approaches. One of the most investigated area is the use of immune based therapies as adjuvant treatment for melanoma, which goads the immune system to produce antibodies against the tumor cells $[3,4]$. These therapies are able to eliminate the tumor with very fewer side effects and establish an immunologic memory, providing long-term protection against tumor recurrence or metastasis [5,6]. In tumor rejection the important requirement is the ability of the immune system to recognize TAA, and to elicit an immune response against the tumor cells $[7,8]$. These antigens range from the $3 \mathrm{D}$ structures of small molecules that are identified by antibodies, to amino acid sequences which are recognized by CTLs. Induction of $\mathrm{T}$ cell mediated immune response is activated by the following two steps. In the first step, TAA derived peptides are thought to bind to empty MHC class-I molecules on dendritic cells, which then activate $\mathrm{T}$ cells by migration to the draining lymph nodes. In the case where the lymphocyte only receives signal 1 , there is no activation of $\mathrm{T}$ cells, resulting in the tumor escaping the attack and a complete failure to stop tumor growth [9]. The barrier to the loss of signal can be overcome by the wide varieties of MAA with a great number of epitopes that are recognized by CTLs. One class of MAA which is identified contains tyrosinase, melan A, gp 100, TRP1 and TRP-2. The first melanocytes differentiating antigen recognized was tyrosinase [8]. This melanosomal membrane protein consists of 529 amino acids, previously known to be required for the melanin synthesis [10]. An antigenic peptide tyrosinase (192-200) with the sequence $\mathrm{S}^{1} \mathrm{EIWR}^{5} \mathrm{DIDF}^{9}$ can be recognized by CTL on the HLA-B44 molecule. According to the recently inferred consensus motif for the anchor residues binding to the HLA-B44, the predominant position for Glu is position 2, Tyr or Phe at positions 9 or 10 and hydrophobic residues at position 3 [11]. The tyrosinase (192-200) nonapeptide fits the consensus very well with Glu at position 2, Phe at position 9 and Ile at position 3 [12]. Among the cells expressing tyrosinase endogenous peptide subtypes of HLA-B44, the HLA- $B^{\star} 4403$ subtype is lysed by the anti-MZ2-C (an antigen produced by the melanoma patients) CTL clone, whereas those of the $B^{\star} 4402$ subtype undergo very insignificant lysis. They differ by a single Asp $\left(B^{\star} 4402\right)$ to Leu $\left(B^{\star} 4403\right)$ substitution in position 156 of the a2-domain [13]. This restricted lysis by selective subtype could be explained either by the binding of the peptides to only one subtype or by differences in the bound peptide structure induced by differences in the groove of the two subtypes. It is observed that the tyrosinase nonapeptide binds to both subtypes. This is consistent with the finding that the consensus motif are similar for both subtypes $B^{\star} 4402$ and $B^{\star} 4403$, since it is based on anchoring residues. It appears, therefore, that different conformations of the peptide in the $B^{\star} 4402$ and $B^{\star} 4403$

*Corresponding author: Evans C Coutinho, Department of Pharmaceutical Chemistry, Bombay College of Pharmacy, Kalina, Santacruz [E], Mumbai 400098, India, E-mail: evans@bcp.edu.in

Received June 19, 2015; Accepted July 13, 2015; Published July 16, 2015

Citation: Coutinho EC, Mishra NB, Bhattacharya D, Srivastava S, Joshi M, Shaikh $M$ et al. (2015) Conformation of the Antigenic Peptide Tyrosinase (192-200) in Water and DMSO- $\mathrm{d}_{6}$ by NMR Spectroscopy and MD Simulations. Pharm Anal Acta 6: 392. doi:10.4172/21532435.1000392

Copyright: (c) 2015 Coutinho EC, et al. This is an open-access article distributed under the terms of the Creative Commons Attribution License, which permits unrestricted use, distribution, and reproduction in any medium, provided the original author and source are credited. 
Citation: Coutinho EC, Mishra NB, Bhattacharya D, Srivastava S, Joshi M, Shaikh M et al. (2015) Conformation of the Antigenic Peptide Tyrosinase (192-200) in Water and DMSO-d $\mathrm{d}_{6}$ by NMR Spectroscopy and MD Simulations. Pharm Anal Acta 6: 392. doi:10.4172/21532435.1000392

Page 2 of 6

grooves are responsible for the differences in the CTL recognition sites [11]. The T cell epitope of tyrosinase (192-200), has shown promising results in clinical trials with fewer side effects and with significant $\mathrm{T}$ cell response. In view of this we have investigated the solution NMR structure of tyrosinase (192-200) by NMR and molecular dynamics simulations. We have investigated its conformation in two solvents i.e. in $\mathrm{H}_{2} \mathrm{O}: \mathrm{D}_{2} \mathrm{O}$ and DMSO- $\mathrm{d}_{6}$. Water provides the environment similar to the body fluids. Based on some observations that the liquid phase in the cytoplasm and the intersynaptic space in receptor binding sites have a viscosity higher than bulk water, it has been suggested that DMSO with a viscosity approximately 2.5 times that of water or other high viscosity solvents may provide a more realistic environment for the study $[14,15]$. Presence of any strong intramolecular hydrogen bonds in the peptides can also be studied as these stronger bonds cannot be disrupted by interaction with DMSO- $\mathrm{d}_{6}[16]$.

\section{Material and Methods}

\section{NMR experiments}

The peptide, $\mathrm{S}^{1} \mathrm{EIWR}^{5} \mathrm{DIDF}^{9}$ was purchased from Bachem, USA. An amount equal to $1 \mathrm{mg}$ of the peptide was dissolved in $0.6 \mathrm{ml}$ of a mixture of $\mathrm{H}_{2} \mathrm{O}(95 \%)$ and $\mathrm{D}_{2} \mathrm{O}(5 \%)$. For the study in DMSO- $\mathrm{d}_{6}$, a similar amount of the peptide was dissolved in $0.6 \mathrm{ml}$ of DMSO- $\mathrm{d}_{6}$ purged in a nitrogen atmosphere to exclude moisture.

The NMR experiments were carried out on $600 \mathrm{MHz}$ and $800 \mathrm{MHz}$ Bruker Avance NMR spectrometers, as per the requirement. The length of the $90^{\circ}$ pulse was calibrated at the beginning of the experiments and the temperature was controlled throughout the experiment to $\pm 0.1 \mathrm{~K}$. 1D proton spectra for the sample in water $\left[\mathrm{H}_{2} \mathrm{O}: \mathrm{D}_{2} \mathrm{O}(95: 5)\right]$ were acquired with a spectral width of $8012 \mathrm{~Hz}, 512$ scans, and digitized with $16 \mathrm{~K}$ data points. Solvent suppression for the sample in water was accomplished with the 3-9-19 WATERGATE pulse sequence. All experiments were recorded with the conventional pulse sequences. The temperature coefficients were measured by recording ${ }^{1} \mathrm{H}$ spectra in the range 290 to $330 \mathrm{~K}$. The spin system assignment for amino acids was carried out using 2D TOCSY [17] with mixing time of $150 \mathrm{~ms}$ and sequential assignment carried out by $2 \mathrm{D}$-ROESY [18] with mixing time of $300 \mathrm{~ms}$. All experiments were run at 300K. For 2D experiments, 512 data points were collected in the time domain. At the beginning of each experiment, 16 dummy scans were collected to allow the system to reach thermal equilibrium. 2D spectra except TOCSY were acquired with a sweep width of $14000 \mathrm{~Hz}$. Typically, 512 FIDs of 2048 complex points were collected. The TOCSY experiment was carried out using spin lock pulse of $100 \mathrm{~ms}$ with 512 experiments at $300 \mathrm{~K}$ and a spectral width of $8012 \mathrm{~Hz}$ for 4096 complex data points. The data were multiplied with $\pi / 4$ and $\pi / 8$ sine bell window functions along the $t_{1}$ and $t_{2}$ axes prior to Fourier transformation. All NMR data were processed using Topspin 3.2 software [19]. In $\mathrm{H}_{2} \mathrm{O}: \mathrm{D}_{2} \mathrm{O}$ the ${ }^{1} \mathrm{H}$ chemical shift were calibrated with the internal standard TSP.

For the sample in DMSO- $\mathrm{d}_{6}, 1 \mathrm{D}$ proton spectra were recorded with a sweep width of $13586 \mathrm{~Hz}$ and $16 \mathrm{~K}$ data points. A total of 1024 scans were accumulated, and an acquisition time of $2.05 \mathrm{~s}$ was used for the peptide in DMSO- $\mathrm{d}_{6} .16$ dummy scans were taken prior to the start of the experiment for thermal equilibrium. All 2D spectral widths were $13586 \mathrm{~Hz}$. The data size in the time domain was 512 points in $\mathrm{t}_{1}$ and 2048 points in $t_{2}$ domains. For each $t_{1}$ value, 96 transients were accumulated. The data were multiplied with $\pi / 4$ and $\pi / 8$ sine bell window functions along the $t_{1}$ and $t_{2}$ axes prior to Fourier transformation. The observed
$512 * 2 \mathrm{k}$ complex data matrices were zero-filled to $2 \mathrm{~K}^{\star} 2 \mathrm{~K}$ points (ROESY and TOCSY). DMSO- $\mathrm{d}_{6}$ was considered as its own internal standard as it distinctly shows a peak at $2.5 \mathrm{ppm}$.

\section{Measurement of inter-proton distances}

ROESY is useful for determining signals arising from protons that are close to each other in space even though they are not covalently bonded. ROESY also detects chemical and conformational exchange among NH protons. The rOe is the result of modulation of the dipoledipole coupling between different nuclear spins by Brownian motion of the molecules in solution. Dipole-dipole interactions are electrostatic interactions present between permanent dipoles in molecules. The rOe intensity varies proportionately with the distance between nuclei separated by a distance less than $5.0 \AA$ [20,21]. The rOe's were converted to distances using the relationship of the rOe intensity to the inverse sixth power of the distance between the protons, as expressed in the following equation.

$$
r_{i j}=r_{k l}\left(I_{k l} / I_{i j}\right)^{1 / 6}
$$

where, $\mathrm{r}_{\mathrm{ij}}$ and $\mathrm{I}_{\mathrm{ij}}$ are the distance and integrated rOe volume between two proton $i$ and $j$ and $r_{k l}$ and $I_{k 1}$ are the same quantities for the pair of reference protons [22]. The inter-nuclear distance between the $\beta-\mathrm{H}_{1}$ and $\beta-\mathrm{H}_{2}$ protons of phenylalanine, $1.732 \AA$ was taken as the reference distance because these protons are non-degenerate and the internuclear distance is invariant with peptide conformations. The distances were cast as restraints using a $\pm 0.3 \AA$ limit to define the upper and lower bounds on the distances.

\section{Dihedral restraints}

The dihedral angle $(\varphi)$ was calculated from the ${ }^{3} \mathrm{~J}_{\mathrm{NHa}}$ coupling constant from the modified Karplus equation, and these were cast as restraints allowing a range of $\pm 10^{\circ}$ on the calculated value $[23,24]$ in the MD simulations.

$$
{ }^{3} \mathrm{~J}_{\mathrm{NHa}}=\mathrm{A}+\mathrm{B} \cos \varphi+\mathrm{C} \cos 2 \varphi
$$

\section{MD simulations}

MD simulations were carried out using GROMACS simulation software package v.4.6.5 [25-28]. The partial charges and potentials for all atoms were assigned using the OPLS-AA 2005 force field [29]. A 3D structure for the sequence was built and saved as PDB format using the Schrödinger module Maestro and the structure was centered in a solvated box containing 26310 TIP3P water molecules [30] or 8027 molecules of DMSO- $\mathrm{d}_{6}$ with the GROMACS software package. The system was neutralized using three $\mathrm{Na}^{+}$and one $\mathrm{Cl}^{-}$as counter ions. Further the system was energy minimized using the steepest descent algorithm [31] for of 1,000,000 steps with a time steps of 2 ps by constraining the $\mathrm{C}-\mathrm{H}$ bonds using the LINCS algorithm. The equilibration in MD was carried out in two steps. The first step (100 ps) was conducted under an NVT (constant number of particles, volume, and temperature) ensemble and the subsequently the system was equilibrated under NPT (constant number of particles, pressure, and temperature) conditions for 100 ps. The production stage with NMR restraints, was performed for 2500 ps.

\section{Results and Discussion}

\section{NMR analysis}

Sequence specific resonance assignment: Sequential assignments were made according to the methods discussed by Wüthrich et al [32]. In sequential assignment the connectivities between ${ }^{1} \mathrm{H}$ spin systems 
Citation: Coutinho EC, Mishra NB, Bhattacharya D, Srivastava S, Joshi M, Shaikh M et al. (2015) Conformation of the Antigenic Peptide Tyrosinase (192-200) in Water and DMSO-d $d_{6}$ by NMR Spectroscopy and MD Simulations. Pharm Anal Acta 6: 392. doi:10.4172/21532435.1000392

Page 3 of 6

of sequentially neighboring amino acids were established. The amino acids were first classified on the basis of their side chain spin system and identified [32]. The Phe-9 residue was identified from the rOe's arising from $\mathrm{H} \beta$ proton to its aromatic rings and the absence of the $\mathrm{H} \gamma$ resonance in the 2D-TOCSY spectrum. Three AMX systems (one Ser and two Asp residues) were identified. Identification of all three $\mathrm{H} \alpha-\mathrm{H} \beta$ connectivities was straight forward from the TOCSY spectrum. The individual Asp residues were distinguished on the basis of their sequential rOe's to their neighboring residues. Ile-3 and Ile7 were identified on the basis of $\mathrm{NH}-\mathrm{H} \alpha-\mathrm{H} \beta-\mathrm{H} \gamma-\mathrm{H} \delta$ connectivities and individual resonances identified by the sequential rOe's to their neighboring residues. Arg- 5 was identified by the presence of $\mathrm{NH}-\mathrm{H} \gamma$ connectivity, where the $\mathrm{H} \gamma$ resonance is comparatively upfield of $\mathrm{H} \beta$. Trp- 4 was assigned by the presence of rOe from the aromatic ring to its $\mathrm{H} \beta$ resonance which is easily observed in the $2 \mathrm{D}$-ROESY spectrum. Glu- 2 was identified on the basis of the upfield shift for its $\mathrm{H} \beta$ resoance, and was confirmed by the rOe to its neighboring residue. Ser-1 was identified by the rOe to Glu-2. After assigning respective resonances for the specific amino acid residues, sequence specific resonance assignment was done by rOe's of 2D ROESY. The cross-peaks observed in the 2D-ROESY spectrum helped in complete sequential assignment. For the peptide in water, the sequence specific resonance assignment was made by walking from the $\mathrm{N}$ terminal to the $\mathrm{C}$ terminal using the rOe's $\left(\mathrm{Ha}_{\mathrm{i}}\right.$ to $\left.\mathrm{NH}_{\mathrm{i}+1}\right)$. Absence of long range rOe's are indicative of a $\beta$-sheet structure in both solvents $[33,34]$. The chemical shifts for the peptide is given in Table $1\left(\right.$ for $\mathrm{H}_{2} \mathrm{O}: \mathrm{D}_{2} \mathrm{O}$ ) and in Table 2(for DMSO- $\mathrm{d}_{6}$ )

\section{Chemical shift index (CSI)}

The CSI is a graph based technique which assigns every assigned chemical shift value to a three state $(-1,0,+1)$ index. The method makes the use of fact that $\alpha \mathrm{H}$ chemical shifts of amino acid residues in helices tends to be shifted upfield (i.e. towards the right side of a NMR spectrum) relative to their random coil values and downfield (i.e. towards the left side of a NMR spectrum) in beta strands. The CSI values of $\mathrm{Ha}$ resonances are used to draw inferences about the secondary structure of the peptide using the rules laid down by Wishart et al [35]. Helical regions and stretches containing turns are usually characterized by a continuous stretch of negative deviations ('-1') from the random coil values for the $\alpha \mathrm{H}$ chemical shifts and a positive deviation $\left({ }^{\prime}+1\right.$ ') in the case of ${ }^{13} \mathrm{C} \alpha$ chemical shifts. $\beta$-turns are characterized by the presence of a continuous stretch of 0 (without any deviation). A $\beta$-strand shows exactly an opposite picture [35-36]. The CSI of the peptide SEIWRDIDF in water and DMSO- $\mathrm{d}_{6}$ are given in Figure 3 . The CSI shows that peptide adopts a predominantly $\beta$ sheet structure in both the solvents.

\section{Temperature coefficients of amide proton resonances}

Temperature coefficients of amide proton embarks upon the presence of intra-molecular hydrogen bonding as chemical shifts are temperature dependent [37]. Temperature coefficient values of the amide proton has been extensively used to predict hydrogen bonding. Small values of the temperature coefficients $(<3.0 \mathrm{ppb} / \mathrm{K})$ of amide protons are usually indicative of intramolecular hydrogen bonds [38]. The temperature dependent of amide proton chemical shift was determined in the temperature range 290 to $330 \mathrm{~K}$. The temperature

\begin{tabular}{|c|c|c|c|c|c|c|c|}
\hline Residue & $\mathrm{NH}$ & $\mathrm{Ha}$ & $H \beta$ & Others & ${ }^{3} \mathrm{~J}_{\mathrm{NHa}}$ & $\begin{array}{c}\text { Torsion angles( } \\
\varphi)\end{array}$ & Temp. coefficient of $\mathrm{NH}$ resonances \\
\hline S1 & - & 4.2 & 3.9 & & & & \\
\hline E2 & 8.39 & 4.44 & 2.33 & Hү $1.92,1.84$ & 7.97 & -159 & -4.8 \\
\hline 13 & 7.91 & 4.24 & 1.69 & $\begin{array}{c}\text { Hy } 1.32,1.01 \\
\text { Hठ } 0.73\end{array}$ & 8.5 & -164 & -6.2 \\
\hline W4 & 7.88 & 4.65 & 2.33 & Ring N-H 9.70 & 8.2 & -161 & -4.3 \\
\hline R5 & 7.84 & 4.49 & $1.74,1.54$ & $\begin{array}{l}\text { Hy } 1.44 \\
\text { Hठ } 3.08 \\
\text { NH } 6.96\end{array}$ & 8.2 & -161 & -5.3 \\
\hline D6 & 8.02 & 4.87 & $2.88,2.72$ & & 7.68 & -156 & -5.3 \\
\hline 17 & 7.76 & 4.18 & 1.76 & $\begin{array}{c}\text { Нү } 1.34,1.0 \\
\text { Н } 0.71\end{array}$ & 8.57 & -165 & -6.3 \\
\hline D8 & 7.99 & 4.86 & $2.80,2.72$ & & 8.27 & -162 & -4.9 \\
\hline F9 & 7.66 & 4.77 & $3.09,2.98$ & $\begin{array}{l}3,5 \mathrm{H} 7.21 \\
2.6 \mathrm{H} 7.10\end{array}$ & 8.57 & -165 & -4.3 \\
\hline
\end{tabular}

Table 1: ${ }^{1} \mathrm{H}$ chemical shifts (in ppm), ${ }^{3} \mathrm{JHA}_{\mathrm{NH}}$ (in $\mathrm{Hz}$ ), torsion angles (in degrees), temperature coefficients of $\mathrm{NH}$ resonances $\left(\mathrm{ppb} / \mathrm{K}\right.$ ) of the peptide $\mathrm{S}^{1} \mathrm{EIWR}^{5} \mathrm{DIDF}^{9}$ in $\mathrm{H}_{2} \mathrm{O}: \mathrm{D}_{2} \mathrm{O}$.

\begin{tabular}{|c|c|c|c|c|c|}
\hline Residue & $\mathrm{NH}$ & $\mathrm{Ha}$ & $\mathrm{H} \beta$ & Others & $\begin{array}{l}\text { Temp. coefficient of } \mathrm{NH} \\
\text { resonances }\end{array}$ \\
\hline $\mathrm{S} 1$ & 7.98 & 4.04 & 3.82 & & -5.0 \\
\hline E2 & 8.39 & 4.41 & 2.62 & Hy $1.78,1.84$ & -6.9 \\
\hline 13 & 7.87 & 4.16 & 1.64 & $\begin{array}{c}\text { Нү } 1.24,0.94 \\
\text { Нठ } 0.63\end{array}$ & -4.5 \\
\hline W4 & 7.86 & 4.91 & 2.33 & $\mathrm{NH} 9.78$ & -4.1 \\
\hline R5 & 8.04 & 4.54 & $2.54,2.39$ & $\begin{array}{l}\mathrm{Hy} 1.65 \\
\mathrm{H} \delta 4.1\end{array}$ & -5.0 \\
\hline D6 & 8.02 & 4.77 & $2.88,2.72$ & & -5.2 \\
\hline 17 & 7.87 & 4.06 & 1.70 & $\begin{array}{l}\text { Нү } 1.32,1.0 \\
\text { Нठ } 0.71\end{array}$ & -5.2 \\
\hline D8 & 7.68 & 4.08 & $2.42,2.29$ & & -4.9 \\
\hline F9 & 7.81 & 4.48 & $3.05,2.90$ & $\begin{array}{l}3,5-\mathrm{H} 7.47 \\
2,6-\mathrm{H} 7.23\end{array}$ & -3.9 \\
\hline
\end{tabular}

Table 2: ${ }^{1} \mathrm{H}$ chemical shifts (in ppm), temperature coefficients of $\mathrm{NH}$ resonances $\left(\mathrm{ppb} / \mathrm{K}\right.$ ) of the peptide $\mathrm{S}^{1} \mathrm{EIWR}^{5} \mathrm{DIDF}^{9}$ in $\mathrm{DMSO}^{-\mathrm{d}_{6}}$ 
Citation: Coutinho EC, Mishra NB, Bhattacharya D, Srivastava S, Joshi M, Shaikh M et al. (2015) Conformation of the Antigenic Peptide Tyrosinase (192-200) in Water and DMSO- $d_{6}$ by NMR Spectroscopy and MD Simulations. Pharm Anal Acta 6: 392. doi:10.4172/21532435.1000392

Page 4 of 6

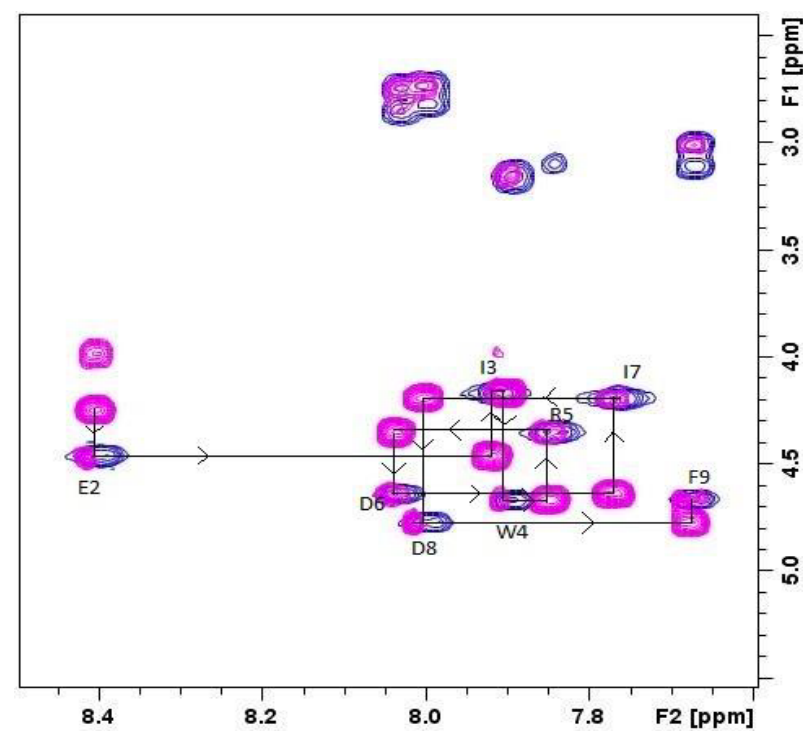

Figure 1: $\mathrm{NH}-\mathrm{Ca}$ fingerprint region of the 2D-ROESY spectrum of the peptide $\mathrm{S}^{1} E I W R^{5} \mathrm{DIDF}^{9}$ recorded with a mixing time $300 \mathrm{~ms}$ in $\mathrm{H}_{2} \mathrm{O}: \mathrm{D}_{2} \mathrm{O}$.

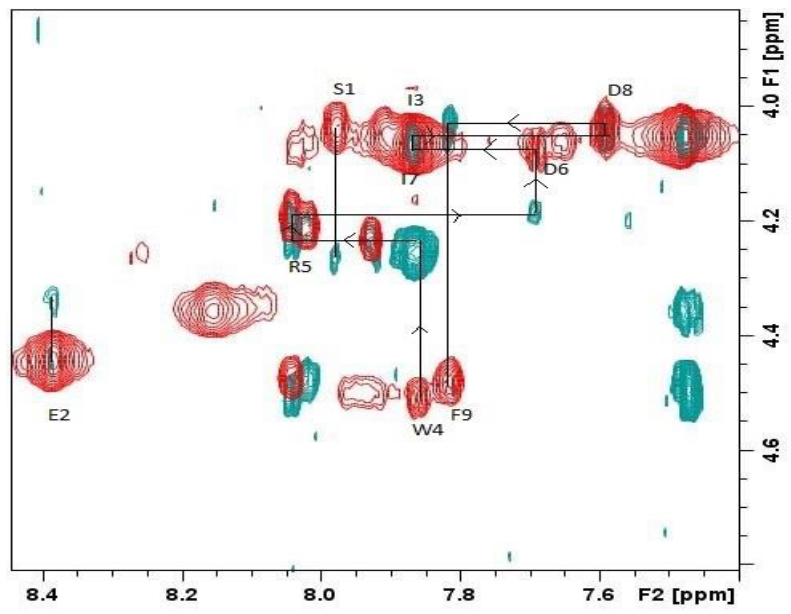

Figure 2: $\mathrm{NH}-\mathrm{Ca}$ fingerprint region of the 2D-ROESY spectrum of the peptide $S^{1} E_{I W R}{ }^{5} I_{D F}{ }^{9}$ recorded with a mixing time $300 \mathrm{~ms}^{\text {in }} \mathrm{DMSO}^{-\mathrm{d}_{6}}$.

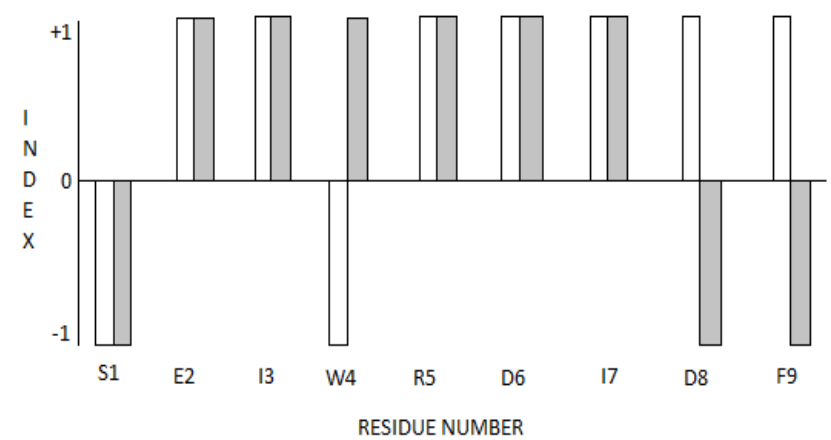

Figure 3: CSI for the peptide $\mathrm{S}^{1}$ EIWR $^{5}$ DIDF$^{9}$ in $\mathrm{H}_{2} \mathrm{O}: \mathrm{D}_{2} \mathrm{O}$ (white) and DMSO- $\mathrm{d}_{6}$ (grey). coefficient of $\mathrm{NH}$ chemicals shifts of the peptide in water are given in Table 1. The values fall in the range of -3.2 to $-6.3 \mathrm{ppb} / \mathrm{K}$. In all cases the chemical shifts varied linearly with temperature. These values indicates that the amide resonances are all exposed to the solvent and suggests a $\beta$ sheet structure for the peptide in the two solvents [33].

\section{${ }^{3} \mathrm{~J}_{\mathrm{NH \alpha}}$ coupling constants}

The ${ }^{3} J_{\mathrm{NH}}$ coupling constant is a function of the dihedral angle $\varphi$ and is used to identify the conformation of the peptide [32]. The dihedral angles $\varphi$ were calculated from the ${ }^{3} \mathrm{~J}_{\mathrm{NHa}}$ values using the Karplus equation $[23,39]$ as explained earlier. The $\varphi$ values so obtained for the peptide in water are given in Tables 1 . The ${ }^{3} \mathrm{~J}_{\mathrm{NH} \alpha}$ coupling constants and the $\varphi$ values extracted from them are characteristic of a predominantly extended backbone conformation [39].

\section{Calculation of 3D structure using NMR constraints}

Restrained molecular dynamics simulations was performed using GROMACS. The statistical analysis of the simulation are given in Table 3. For the peptide in water, of the 100 structures sampled from the MD trajectory, 5 structures with the lowest global deviations from the input restraints were selected. A superposition of the backbone atoms of the 5 conformers is shown in Figure 4. The NMR structure with the lowest violations of imposed restraints is depicted in Figure 5. The backbone torsion angles $(\varphi, \psi)$ for $\mathrm{S}^{1} \mathrm{EIWR}^{5} \mathrm{DIDF}^{9}$ averaged over the entire MD trajectory are given in Table 4 . The Ramachandran plots are given in Figure $4\left(\mathrm{H}_{2} \mathrm{O}: \mathrm{D}_{2} \mathrm{O}\right)$ and Figure $5\left(\right.$ DMSO- $\left.\mathrm{d}_{6}\right)$. The mean global RMSD was found to be $0.30 \AA$.

For DMSO- $\mathrm{d}_{6}$, of the 100 structures, 6 structures with the lowest global deviations from the input restraints were selected. A superposition of the backbone atoms of the peptide in the 6 conformations is shown in Figure 6. The NMR structure with the lowest violations of the imposed restraints is depicted in Figure 7. The mean global RMSD was found to be $0.28 \AA$.

\section{Conclusions}

The antigenic epitope tyrosinase (192-200) has shown wide applicability in the treatment of the melanoma associated cancers. It is significantly responsible for $\mathrm{T}$ cell response against tumor cells which is predominantly dependent upon the conformational structure of the peptide. In this study we have underlined the NMR structure of the antigenic epitope in two media i.e. $\mathrm{H}_{2} \mathrm{O}: \mathrm{D}_{2} \mathrm{O}$ (95:5) and DMSO- $\mathrm{d}_{6}$. From the NMR parameters i.e. ${ }^{3} \mathrm{~J}_{\mathrm{NH} \alpha}$ coupling constants, temperature coefficients of $\mathrm{NH}$ chemical shifts and CSI values it was deduced that the peptide in both solvents exhibits an extended $\beta$ sheet conformation. From this it may be concluded that the peptide in a $\beta$ sheet conformation perhaps binds to TCR to elicit the biological response. This could open new areas of research for optimizing synthetic peptidomimetics specifically targeting TCR thus aiding the rational design of peptides that can bind to T-cells.

\section{Conflict of Interest}

The authors confirm that this article has no conflict of interest.

\section{Acknowledgment}

We acknowledge the NMR facilities provided by the National Facility for High Field NMR located at Tata Institute of Fundamental Research, Mumbai and the 
Citation: Coutinho EC, Mishra NB, Bhattacharya D, Srivastava S, Joshi M, Shaikh M et al. (2015) Conformation of the Antigenic Peptide Tyrosinase

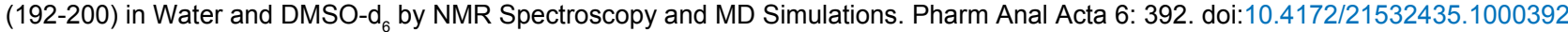

\begin{tabular}{|c|c|c|}
\hline & Distance restraints & \\
\hline \multirow{2}{*}{ All } & $\mathrm{H}_{2} \mathrm{O}$ & 52 \\
& $\mathrm{DMSO}-\mathrm{d}_{6}$ & 27 \\
\hline \multirow{2}{*}{ Intra residue } & $\mathrm{H}_{2} \mathrm{O}$ & 44 \\
& $\mathrm{DMSO}-\mathrm{d}_{6}$ & 22 \\
\hline \multirow{2}{*}{ Sequential } & $\mathrm{H}_{2} \mathrm{O}$ & 8 \\
\hline NOE violations $(>0.3 \AA)$ & $\mathrm{DMSO}-\mathrm{d}_{6}$ & 5 \\
\hline & $\mathrm{H}_{2} \mathrm{O}$ & 3 \\
\hline Maximum & $\mathrm{DMSO}-\mathrm{d}_{6}$ & 5 \\
\hline Minimum & $\mathrm{RMSD}(\AA)$ & 0.61 \\
& $\mathrm{H}_{2} \mathrm{O}$ & 0.48 \\
\hline & $\mathrm{DMSO}-\mathrm{d}_{6}$ & 0.08 \\
\hline
\end{tabular}

Table 3: Structural statistics for the tyrosinase (192-200) in $\mathrm{H}_{2} \mathrm{O}: \mathrm{D}_{2} \mathrm{O}$ and DMSO- $\mathrm{d}_{6}$

\begin{tabular}{|c|c|c|c|c|}
\hline \multirow{2}{*}{$\begin{array}{l}\text { Amino acid } \\
\text { residues }\end{array}$} & \multicolumn{2}{|c|}{$\mathrm{H}_{2} \mathrm{O}: \mathrm{D}_{2} \mathrm{O}$} & \multicolumn{2}{c|}{ DMSO- $_{6}$} \\
\hline & $\varphi$ & $\Psi$ & $\Phi$ & $\Psi$ \\
\hline $\mathrm{S}^{1}$ & - & 143 & - & 129 \\
\hline $\mathrm{E}^{2}$ & -137 & 130 & -142 & 152 \\
\hline $\mathrm{I}^{3}$ & -135 & 123 & -134 & 126 \\
\hline $\mathrm{W}^{4}$ & -149 & 144 & -139 & 122 \\
\hline $\mathrm{R}^{5}$ & -156 & 134 & -137 & 130 \\
\hline $\mathrm{D}^{6}$ & -146 & 119 & -125 & 115 \\
\hline $\mathrm{I}^{7}$ & -149 & 128 & -137 & 118 \\
\hline $\mathrm{D}^{8}$ & -148 & 133 & -144 & 136 \\
\hline $\mathrm{F}^{9}$ & -135 & - & -131 & - \\
\hline
\end{tabular}

Table 4: The backbone torsion angles $(\varphi, \psi)$ for $\mathrm{S}^{1} \mathrm{EIWR}^{5} \mathrm{DIDF}^{9}$ averaged over the entire MD trajectory.

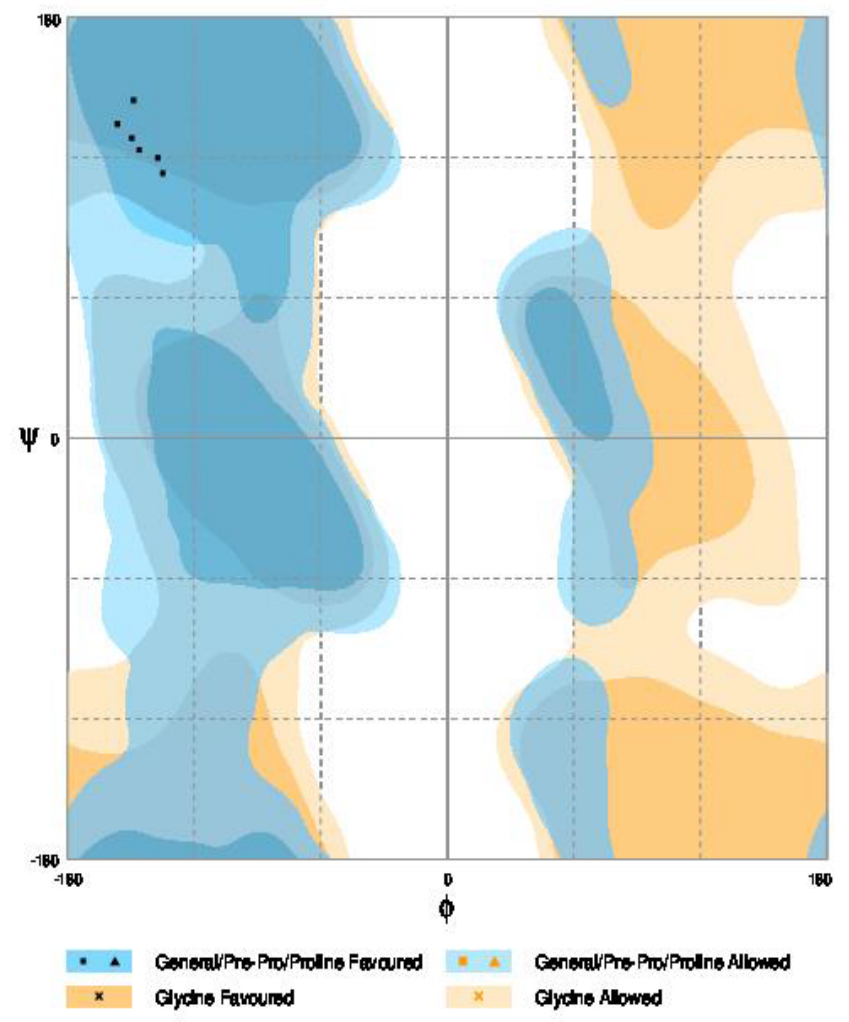

Figure 4: Ramachandran plot for $\mathrm{S}^{1} E I W R^{5}$ DIDF $^{9}$ in $\mathrm{H}_{2} \mathrm{O}: \mathrm{D}_{2} \mathrm{O}$.

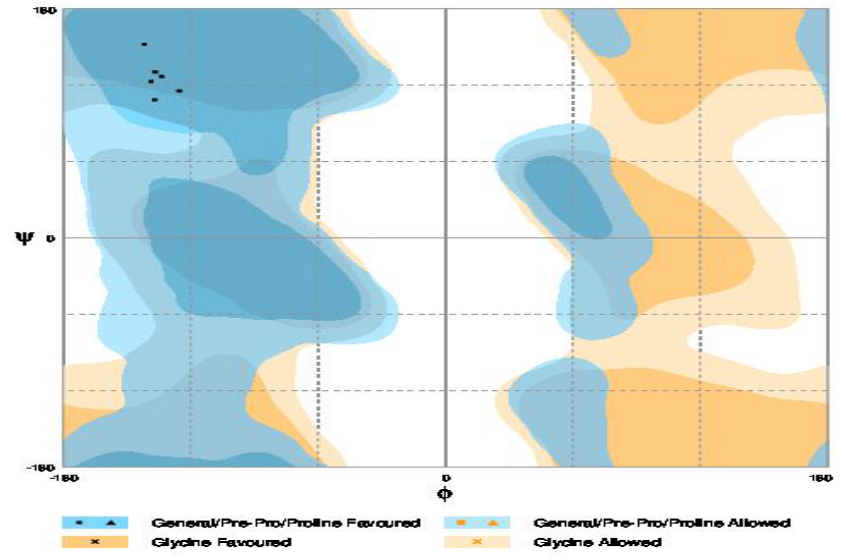

Figure 5: Ramachandran plot for $S^{1} E_{I W R^{5} D^{2} F^{9} \text { in DMSO-d }}$.

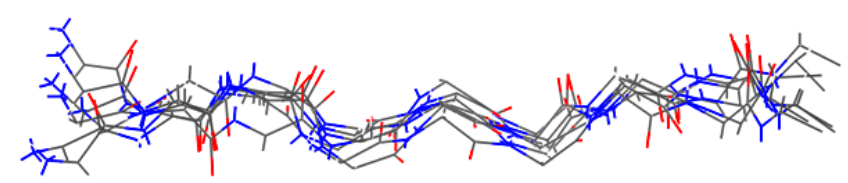

Figure 6: A superposition of the backbone atoms of the 5 best NMR conformers of the peptide in water.

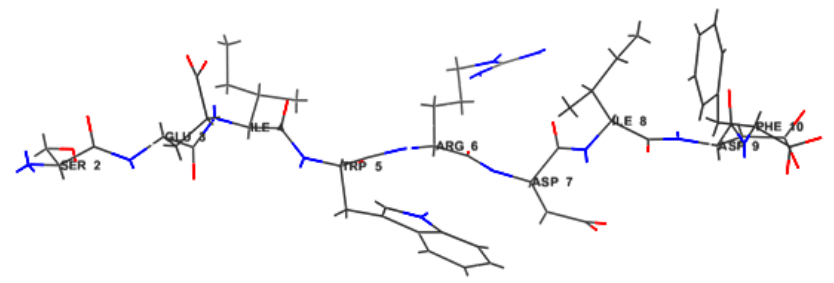

Figure 7: NMR structure of $S^{1} E I W R^{5} D_{I D F}$ obtained from restrained MD in water.

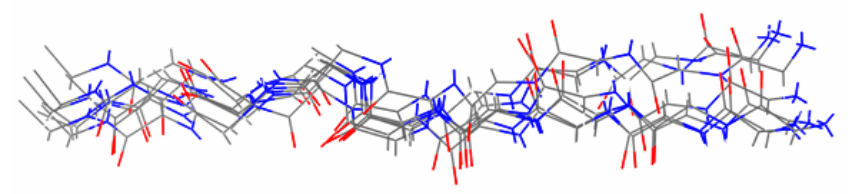

Figure 8: Superposition of the backbone atoms of the peptide in the six conformations seen in DMSO- $d_{6}$.

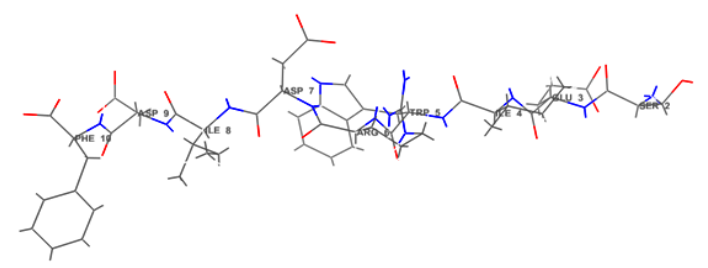

Figure 9: The NMR structure of $S^{1}$ EIWR $^{5}$ DIDF $^{9}$ in DMSO- $d_{6}$. 
Citation: Coutinho EC, Mishra NB, Bhattacharya D, Srivastava S, Joshi M, Shaikh M et al. (2015) Conformation of the Antigenic Peptide Tyrosinase (192-200) in Water and DMSO- $d_{6}$ by NMR Spectroscopy and MD Simulations. Pharm Anal Acta 6: 392. doi:10.4172/21532435.1000392

computational and infrastructural facilities provided by Department of Science and Technology, New Delhi through their SERB program (SR/FST/LSI-163/2003; SR/ SO/HS-0117/2012) and Council of Scientific and Industrial Research, New Delhi (01/2399/10/EMRII).

\section{References}

1. Kwon BS1 (1993) Pigmentation genes: the tyrosinase gene family and the pmel 17 gene family.

2. MacKie RM (1995) Melanoma prevention and early detection. Br Med Bull 51: 570-583.

3. Ohman Forslund K, Nordqvist K (2001) The melanoma antigen genes--any clues to their functions in normal tissues? Exp Cell Res 265: 185-194.

4. Morton DL, Foshag LJ, Hoon DS, Nizze JA, Famatiga E, et al. (1992) Prolongation of survival in metastatic melanoma after active specific immunotherapy with a new polyvalent melanoma vaccine. Ann Surg 216: 463-482.

5. Jimenez M, Nieto J, Rico M, Santoro J, Herranz J (1986) A study of the NH NMR signals of Gly-Gly-X-Ala tetrapeptides in $\mathrm{H} 2 \mathrm{O}$ at low temperature. Journal of Molecular Structure 143: 435-438.

6. Banchereau J, Palucka AK, Dhodapkar M, Burkeholder S, Taquet N, et al. (2001) Immune and clinical responses in patients with metastatic melanoma to CD34(+) progenitor-derived dendritic cell vaccine. Cancer Res 61: 6451-6458.

7. Van den Eynde B, Lethe B, Van Pel A, Boon T (1992) Tumor Rejection Antigens and Immune Surveillance. Modern Trends in Human Leukemia IX pp: 279-285.

8. Kirkin AF, Dzhandzhugazyan K, Zeuthen J (1998) Melanoma-associated antigens recognized by cytotoxic T lymphocytes. APMIS 106: 665-679.

9. Scheibenbogen C, Schadendorf D, Bechrakis NE, Nagorsen D, Hofmann U, et al. (2003) Effects of granulocyte-macrophage colony-stimulating factor and foreign helper protein as immunologic adjuvants on the T-cell response to vaccination with tyrosinase peptides. Int J Cancer 104: 188-194.

10. Bouchard B, Fuller BB, Vijayasaradhi S, Houghton AN (1989) Induction of pigmentation in mouse fibroblasts by expression of human tyrosinase cDNA. J Exp Med 169: 2029-2042.

11. Fleischhauer K, Avila D, Vilbois F, Traversari C, Bordignon C (1994) Characterization of natural peptide ligands for HLA-B*4402 and $-B^{*} 4403$ : implications for peptide involvement in allorecognition of a single amino acid change in the HLA-B44 heavy chain. Tissue Antigens 44: 311-317.

12. Brichard VG, Herman J, Van Pel A, Wildmann C, Gaugler B, et al. (1996) A tyrosinase nonapeptide presented by HLA-B44 is recognized on a human melanoma by autologous cytolytic T lymphocytes. Eur J Immunol 26: 224-230.

13. Kawakami Y, Eliyahu S, Delgado CH, Robbins PF, Sakaguchi K, et al. (1994) Identification of a human melanoma antigen recognized by tumor-infiltrating lymphocytes associated with in vivo tumor rejection. Proceedings of the National Academy of Sciences of the United States of America 91: 6458-6462.

14. Amodeo P, Motta A, Picone D, Saviano G, Tancredi T, et al. (1991) Viscosity as a conformational sieve. NOE of linear peptides in cryoprotective mixtures. Journal of Magnetic Resonance 95: 201-207.

15. Shen CL, Murphy RM (1995) Solvent effects on self-assembly of beta-amyloid peptide. Biophys J 69: 640-651.

16. Jackson M1, Mantsch HH (1991) Beware of proteins in DMSO. Biochim Biophys Acta 1078: 231-235.

17. Bax A, Davis DG (1985) MLEV-17-based two-dimensional homonuclear magnetization transfer spectroscopy. Journal of Magnetic Resonance 65: 355360 .

18. Bax A, Davis DG (1985) Practical aspects of two-dimensional transverse NOE spectroscopy. Journal of Magnetic Resonance 63: 207-213.

19. Donaldson AF. TopSPIN User Manual.

20. Van de Ven F, Blommers M, Schouten R, Hilbers C (1991) Calculation of interproton distances from NOE intensities. A relaxation matrix approach without requirement of a molecular model. Journal of Magnetic Resonance 94: 140-151.

21. James TL, Young GB, Broido MS, Keepers JW, Jamin N, et al. ( 1985) Quantitative internuclear distancesvia two-dimensional nuclear magnetic resonance spectra: A test case and a DNA octamer duplex. Journal of Biosciences 8: 553-562.
22. Jackman LM, Sternhell S, DHR Barton, W Doering (2013) Application of Nuclear Magnetic Resonance Spectroscopy in Organic Chemistry $\left(2^{\text {nd }}\right.$ edn $)$ International Series in Organic Chemistry, Elsevier.

23. Karplus M (1963) Vicinal proton coupling in nuclear magnetic resonance. Journal of the American Chemical Society 85: 2870-2871.

24. Malde AK, Srivastava SS, Coutinho EC (2007) Understanding interactions of gastric inhibitory polypeptide (GIP) with its G-protein coupled receptor through NMR and molecular modeling. J Pept Sci 13: 287-300.

25. Hess B, Kutzner C, Van Der Spoel D, Lindahl E (2008) GROMACS 4: algorithms for highly efficient, load-balanced, and scalable molecular simulation. J Chem Theory Comput 4: 435-447.

26. Van Der Spoel D, Lindahl E, Hess B, Groenhof G, Mark AE, et al. (2005) GROMACS: fast, flexible, and free. J Comput Chem 26: 1701-1718.

27. Lindahl E, Hess B, Van Der Spoel D (2001) GROMACS 3.0: a package for molecular simulation and trajectory analysis. Molecular modeling annual 7 : 306-317.

28. Berendsen HJ, van der Spoel D, van Drunen R (1995) GROMACS: A messagepassing parallel molecular dynamics implementation. Computer Physics Communications 91: 43-56.

29. Jorgensen WL (1998) OPLS force fields. Encyclopedia of computationa chemistry.

30. Price DJ, Brooks CL 3rd (2004) A modified TIP3P water potential for simulation with Ewald summation. J Chem Phys 121: 10096-10103.

31. Luenberger DG (1973) Introduction to linear and nonlinear programming Addison-Wesley Reading, MA.

32. Wüthrich K (1986) NMR of proteins and nucleic acids: Wiley New York.

33. Desal P, Coutinho E, Srivastava S, Haq W, Katti S (2002) Conformation of an immunoreactive undecapeptide fragment (10-20) of Asp $f 1$ by NMR and molecular modeling. Letters in Peptide Science 9: 21-34.

34. Bhattacharya D, Mishra N, Coutinho E, Srivastava S, Pissurlenkar R (2015) Conformational Study on Pheromonotropin neuropeptide using NMR and Molecular Dynamics. Pharm Anal Acta 6: 2.

35. Wishart DS, Sykes BD, Richards FM (1992) The chemical shift index: a fast and simple method for the assignment of protein secondary structure through NMR spectroscopy. Biochemistry 31: 1647-1651.

36. Tikhele SH, Pissurlenkar RR, Srivastava S, Saran A, Coutinho EC (2010) Mapping interactions of gastric inhibitory polypeptide with GIPR N-terminus using NMR and molecular dynamics simulations. Journal of peptide science an official publication of the European Peptide Society 16: 383-391.

37. Ohnishi M, Urry DW (1969) Temperature dependence of amide proton chemical shifts: the secondary structures of gramicidin $S$ and valinomycin. Biochem Biophys Res Commun 36:194-202.

38. Tripathi J, Desai P, Srivastava S, Cuthino E (2009) Conformational studies of nonapeptide using NMR. Indian journal of chemistry Section B, Organic including medicinal 48: 103.

39. Bystrov VF (1976) Spin—spin coupling and the conformational states of peptide systems. Progress in Nuclear Magnetic Resonance Spectroscopy 10: 41-82. 